\title{
Comparison of supraintercondylar and supracondylar femur fractures treated with condylar buttress plates
}

\author{
Chun-Jui Weng ${ }^{*}$, Chi-Chuan Wu, Kuo-Fun Feng, I-Chuan Tseng, Po-Cheng Lee and Yu-Chih Huang
}

\begin{abstract}
Background: Treatment of supraintercondylar (AO/OTA 33-C) and supracondylar (AO/OTA 33-A) femur fractures is generally challenging. Standard treatments include open reduction and internal fixation. However, optimal implants are now being well-defined. This study focus on the comparison between clinical and functional outcomes of fractures treated with condylar buttress plates (CBPs).

Methods: We treated 87 patients with supraintercondylar or supracondylar femur fracture from 2004 to 2008, including 30 supraintercondylar and 24 supracondylar fractures treated with CBPs. Both knee and function scores (per Knee Society) were given to clinical and functional outcomes, and concomitant knee function was assessed per Mize criteria.

Results: Union rate of supraintercondylar fractures was $90 \%$ (27/30) and supracondylar fractures was 91.7\% (22/24) $(P=0.68)$. In supraintercondylar group, $16.7 \%$ revealed postoperative varus deformity, whereas none in supracondylar group $(P=0.045)$. Knee Society knee score was 73.6 in supraintercondylar group and 85.5 in supracondylar group $(P=0.009)$; and function score was 62.5 in supraintercondylar group and 83.1 in supracondylar group $(P=0.023)$. A satisfactory result based on modified Mize criteria was achieved in $50 \%$ of supraintercondylar fractures and in $79.1 \%$ of supracondylar fractures $(P=0.09)$.

Conclusions: Use of CBPs for supraintercondylar and supracondylar femur fractures treatment led to a high union rate. However, a high rate of varus deformity occurred in patients with supraintercondylar but not supracondylar fractures. Moreover, CBP treatment in patients with supracondylar fractures led to better functional outcomes than those with supraintercondylar fractures.
\end{abstract}

Keywords: Supraintercondylar fractures, Supracondylar fractures, Femur, Condylar buttress plates

\section{Background}

Treatment of distal femur fractures remains clinically challenging. Owing to improvements in surgical techniques and modern implant designs, open reduction and internal fixation (ORIF) is thought to be the standard treatment by many orthopedic surgeons. In 1960s, in a series of 213 cases, Stewart and colleagues compared surgical and conservative treatment of distal femur fractures and concluded that Kirschner pin traction was recommended as the treatment of choice, with higher acceptable results than with ORIF [1]. Neer and colleagues also reached the same conclusion [2]. They

\footnotetext{
* Correspondence: jim_weng@hotmail.com

Department of Orthopedic Surgery, Chang Gung Memorial Hospital, Chang Gung University, No. 5, Fu-Hsin Street, Kweishan, Taoyuan, Taiwan
}

analyzed 110 cases and found that compared with operative treatment, non-operative treatment led to superior outcomes (54 vs. $90 \%$, respectively). However, surgical techniques and implants were not as good as modern days.

In 1970s, Arbeitsgemeinschaft für Osteosynthesefragen (AO) reported good or excellent results in $74 \%$ of 112 supracondylar femur fractures treated with a condylar plate. Studies by Schatzker and colleagues [3] reported good or excellent results in 73.5-75\% patients following ORIF. He emphasized the importance of early motion and stable fixation. Since the 1970s, ORIF has gained increasing popularity. Various types of internal fixations have been used to achieve anatomic reduction and rigid fixation. Plate systems are the favored method of treatment, including condylar buttress plates (CBPs), 
dynamic condylar screws, fix-angle condylar plates, and locking plates [3-12].

According to our previous study, AO/OTA 33-C fracture, also called supraintercondylar femur fractures, treated with a CBP resulted in a union rate of $90 \%$ [12]. However, a high incidence of varus deformity (16.7 \%) also was noted. A review of the current literature revealed no published studies that compare clinical and functional outcomes between AO/OTA 33- C(supraintercondylar fractures) and AO/OTA 33-A fracture (supracondylar femur fractures) treated with a CBP. The aim of the present study was to retrospectively evaluate clinical and functional outcomes of both types of fracture treated with a CBP and determine the suitability of such a treatment modality.

\section{Methods}

During 2004/3-2008/11, we treated 87 consecutive adult patients ( $>16$ years of age) with closed supraintercondylar or supracondylar femur fracture at our institution. Among these, 60 were treated with ORIF with a CBP. The remaining 27 patients were treated with another internal fixator, such as a locking plate, fixed-angled plate, dynamic condylar plate, or retrograde nailing. We excluded those who were lost to follow up with a year of the surgery. Finally, 54 patients were included in the final evaluation. Among these, 30 had supraintercondylar and 24 had supracondylar fractures. All fractures were categorized according to the AO classification [13].

In the emergency department, the vital signs of each patient were stabilized first. A lower leg skin traction or long leg splint was applied after admission. Operative treatment was arranged for as early as possible. All operations were performed by a group of experienced surgeons with a traditional lateral approach. The patient was placed in the supine position and a pneumatic tourniquet was used. A CBP (Synthes, Bettlach, Switzerland) was applied after fracture reduction. Supplementary screw fixation was used for additional support in complicated fractures. Postoperatively, knee immobilization was not needed.

Active range of motion exercise was initiated after surgery and patients were encouraged to ambulate with a walker or crutches. Radiographs were taken postoperatively during hospitalization and at every outpatient department (OPD) visit. The first OPD visit was arranged within 2 weeks after discharge from the hospital, and the interval between every OPD visit was prolonged until bony union was achieved.

Fracture union and bony alignment were evaluated radiographically by performing anteroposterior and lateral plain radiographs of the injured leg. We defined fracture union as trabeculae crossing the fracture site on serial roentgenograms. On the contrary, fracture nonunion was defined as the absence of trabeculae crossing the fracture on plain radiographs at postoperative 1-year or as the need for revision surgery within 1 year after primary ORIF surgery. With respect to bony alignment, we measured the lateral distal femoral angle (LDFA) on each plain radiograph [14]. This angle measures the intersection between the anatomic axis and the horizontal line tangential to the subchondral surface of the femoral condyles. The normal value of the LDFA falls between $79^{\circ}$ and $83^{\circ}$ [15]. We modified the criteria originally suggested by Schatzker and Lambert [3] and modified by Mize [5]. We defined varus deformity as an LDFA $5^{\circ}$ above the upper limit of normal $\left(81^{\circ} \pm 2^{\circ}\right)$ [15] That is, an LDFA $>88^{\circ}$ was defined as varus deformity. On the contrary, valgus deformity was defined as an LDFA $<69^{\circ}$, which is $10^{\circ}$ below the lower limit of normal. Andriacchi and colleagues [16] and Zhao and colleagues [17] found that loads on the medial compartment of the knee are greater than those on the lateral compartment of the knee during the stance phase of gait. Therefore, we hypothesize that the knee joint is more vulnerable to varus deformity than valgus deformity, due to more loads and stresses on the medial aspect of the knee. Thus, varus deformity should be defined more strictly. Therefore, we evaluated functional outcome with the criteria suggested by Mize, but with a modified definition of varus deformity.

For each fracture, we assessed clinical and functional outcomes of the knee according to 2 scoring systems: Knee Society score (Table 1) [18] and the criteria suggested by Schatzker and Lambert [3], which was further modified by Mize (Table 2) [5]. The Knee Society score included both knee and function scores [18]. The knee score included 4 parameters: pain, range of motion, stability, and deductions. The function score was comprised of functional evaluation of walking and stair climbing. We further modified the criteria suggested by Mize for outcome evaluation [5]. A satisfactory result included an excellent or good score.

Data were analyzed by using the Student's $t$ test, Fisher's exact test, and Chi-square test, with the SPSS data analysis program (Version 16, Chicago, IL). We set statistical significance at $P<0.05$.

\section{Results}

In the supraintercondylar group, 30 of 34 patients (17 men and 13 women) received regular OPD follow-up for more than 1 year (range, 13-89 months; average, 29 months). The 1-year follow-up rate was $88.2 \%$. The average age at the time of fracture was 42.9 years (range, 16-91 years). Fracture occurred on the left side in 10 patients and the right side in 20 patients. As for fracture type, 10 were $\mathrm{C} 1,14$ were $\mathrm{C} 2$, and 6 were C3. Twentyseven patients achieved bony union, resulting in a union 
Table 1 The knee society-based knee and function scores

\begin{tabular}{|c|c|c|c|}
\hline Parameter & Points & Parameter & Points \\
\hline Pain & & Functions & \\
\hline None & 50 & Walking & \\
\hline Mild or occasional & 45 & Unlimited & 50 \\
\hline Stairs only & 40 & $>10$ blocks & 40 \\
\hline Walking and stairs & 30 & 5-10 blocks & 30 \\
\hline Moderate & & $<5$ blocks & 20 \\
\hline Occasional & 20 & Housebound & 10 \\
\hline Continual & 10 & Inability to walk & 0 \\
\hline Severe & 0 & Stairs & \\
\hline Range of motion & & Normal up and down & 50 \\
\hline $5^{\circ}=1$ point & 25 & $\begin{array}{l}\text { Normal up; down } \\
\text { holding rail }\end{array}$ & 40 \\
\hline Stability & & Up and down holding rail & \\
\hline Anteroposterior & & $\begin{array}{l}\text { Up holding rail; inability } \\
\text { to walk down }\end{array}$ & 30 \\
\hline$<5 \mathrm{~mm}$ & 10 & Inability to climb stairs & 15 \\
\hline $5-10 \mathrm{~mm}$ & 5 & Subtotal & - \\
\hline $10 \mathrm{~mm}$ & 0 & Deductions (minus) & \\
\hline Mediolateral & & Cane & 5 \\
\hline$<5^{\circ}$ & 15 & 2 canes & 10 \\
\hline $6^{\circ}-9^{\circ}$ & 10 & Crutches or walker & 20 \\
\hline $10^{\circ}-14^{\circ}$ & 5 & Total deductions & - \\
\hline $15^{\circ}$ & 0 & Function score & - \\
\hline \multicolumn{4}{|l|}{ Deductions (minus) } \\
\hline \multicolumn{4}{|l|}{ Flexion contracture } \\
\hline $5^{\circ}-10^{\circ}$ & 2 & & \\
\hline $10^{\circ}-15^{\circ}$ & 5 & & \\
\hline $15^{\circ}-20^{\circ}$ & 10 & & \\
\hline$>20^{\circ}$ & 15 & & \\
\hline \multicolumn{4}{|l|}{ Extension lag } \\
\hline$<10^{\circ}$ & 5 & & \\
\hline $10^{\circ}-20^{\circ}$ & 10 & & \\
\hline$>20^{\circ}$ & 15 & & \\
\hline \multicolumn{4}{|l|}{ Alignment } \\
\hline $5^{\circ}-10^{\circ}$ & 0 & & \\
\hline $0^{\circ}-4^{\circ}$ & $\begin{array}{l}3 \text { points per } \\
\text { degree }\end{array}$ & & \\
\hline $11^{\circ}-15^{\circ}$ & $\begin{array}{l}3 \text { points per } \\
\text { degree }\end{array}$ & & \\
\hline Other & 20 & & \\
\hline \multicolumn{4}{|l|}{ Total deductions } \\
\hline Knee score & & & \\
\hline (if total is a negati & number, sco & is 0 ) & \\
\hline
\end{tabular}

Table 2 Modification of Mize-Modified Criteria (original criteria suggested by Schatzker and Lambert)

\begin{tabular}{|c|c|}
\hline Grading & Description \\
\hline Excellent & $\begin{array}{l}\text { All of the following: loss of flexion, }<10^{\circ} \text {; full extension; } \\
\text { no varus, valgus, or rotatory deformity; no pain; perfect } \\
\text { joint congruency }\end{array}$ \\
\hline Good & $\begin{array}{l}\text { No more than any } 1 \text { of the following: loss of flexion, } \\
>20^{\circ} \text {; loss of extension, }>10^{\circ} \text {; varus deformity, }>5^{\circ} \text {; } \\
\text { valgus deformity, }>10^{\circ} \text {; minimum pain }\end{array}$ \\
\hline Fair & Any 2 of the criteria listed in the previous category \\
\hline Failure & $\begin{array}{l}\text { Any of the following: flexion, } \leq 90^{\circ} \text {; varus deformity, } \\
>10^{\circ} \text {; valgus deformity, }>15^{\circ} \text {; joint incongruency; } \\
\text { disabling pain, irrespective of radiographic appearance }\end{array}$ \\
\hline
\end{tabular}

${ }^{a}$ Alignment was determined by measuring the anatomic lateral distal femoral angle (normal range $=79^{\circ}-83^{\circ}$ )

rate of $90 \%(27 / 30$.) Two patients demonstrated fracture nonunion after postoperative 1 -year, and 1 patient who did not show callus formation 9 months after surgery underwent revision surgery with intramedullary nailing (Fig. 1). The average time to union was 6.4 months (range, 2-12 months). Complications included deep infection (2 knees, $6.7 \%$ ), knee stiffness (4 knees, $13.3 \%$ ), and varus deformity (5 knees, $16.7 \%$ ) (Fig. 2). The 2 patients with deep infection were treated with antibiotics and surgical debridement; 1 of the 2 developed chronic osteomyelitis.

In the supracondylar group, 24 of 26 patients (9 men and 15 women) received more than 1 year of OPD follow-up (range, 14-65 months; average, 26 months), with a 1-year follow-up rate of $92.3 \%$. The average age at the time of fracture was 54.6 years (range, 18-93 years). Fracture occurred on the left side in 11 patients and the right side in 13 patients. As for fracture type, 12 were $\mathrm{A} 1,12$ were $\mathrm{A} 2$, and no patient was $\mathrm{A} 3$. Twentytwo of 24 patients achieved bony union (Fig. 3), resulting in a union rate of $91.7 \%$. No patient developed deep infection or varus deformity. However, 2 patients showed nonunion and received revision surgery, eventually achieving bony union uneventfully. The average time to union was 5 months (range, 3-10 months).

In comparing clinical results between supraintercondylar and supracondylar fractures, both groups achieved a high union rate $(90 \%$ vs. $91.7 \%, P=0.68)$ and a comparable union time (6.4 months vs. 5 months, $P=0.19$ ). However, there were 5 patients in the supraintercondylar group with postoperative varus deformity, but no patient appeared malaligned radiographically in the supracondylar group; this difference was statistically significant $(P=0.045)$.

Functional outcome was evaluated with 2 systems. In the supraintercondylar group, the mean Knee Society knee score was 73.6 (range, 18-100); among them, $50 \%$ $(15 / 30)$ had an excellent score, $23.3 \%(7 / 30)$ had a good score, $13.3 \%(4 / 30)$ had a fair score, and $13.3 \%(4 / 30)$ had a poor score. The satisfactory rate was $73 \%(22 / 30)$. 


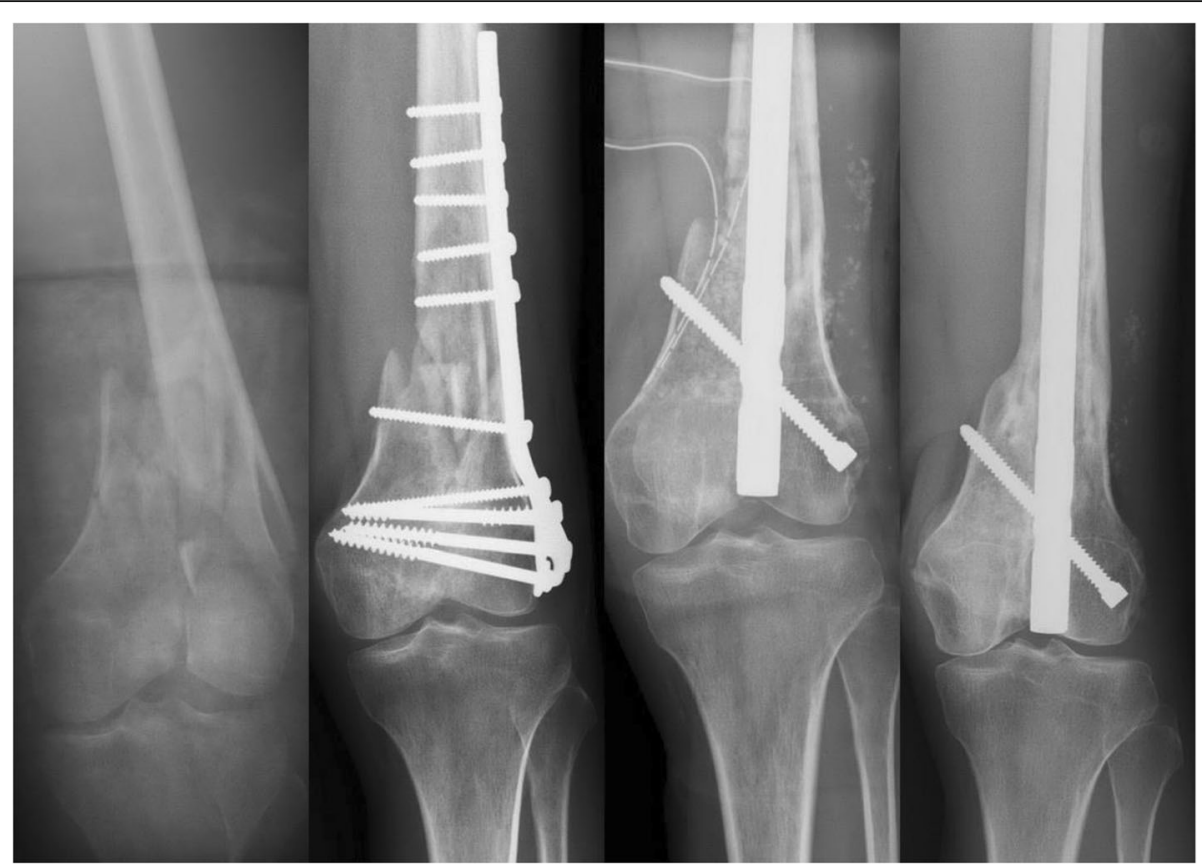

Fig. 1 From left to right: left supraintercondylar fracture; 9-months postoperative; anteroposterior (AP) image taken after revision surgery with intramedullary nail insertion; follow-up AP image, revealing bony union

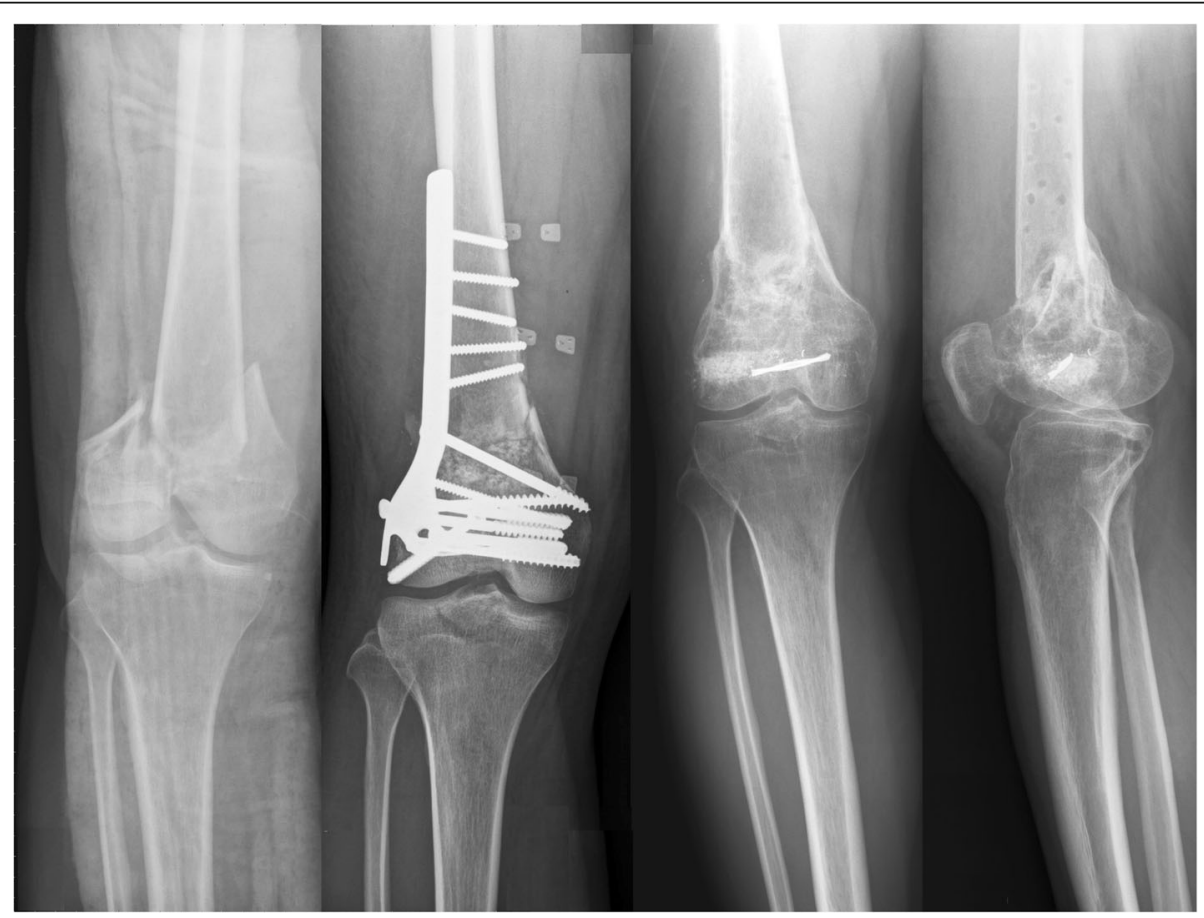

Fig. 2 From left to right: right supraintercondylar fracture; postoperative anteroposterior (AP) image; AP and lateral images taken 1 year after surgery, revealing bony union but varus deformity 


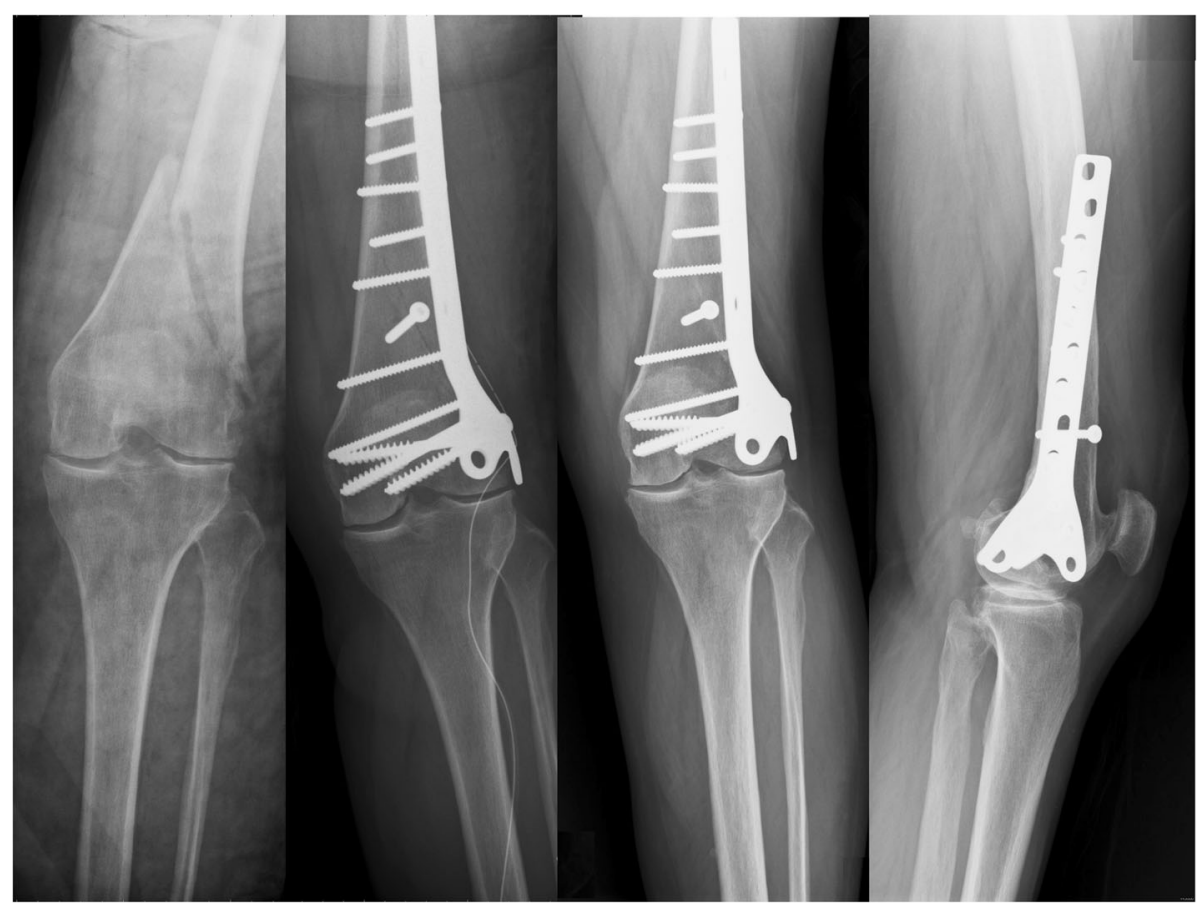

Fig. 3 From left to right: left supracondylar fracture; postoperative anteroposterior (AP) image; AP and lateral images taken 6 months after surgery, revealing bony union and no varus/valgus deformity

The average Knee Society function score was 62.5 (range, 0-100); among these, $46.7 \%(14 / 30)$ had an excellent score, $3.3 \%(1 / 30)$ had a good score, $6.7 \%(2 / 30)$ had a fair score, and $43.3 \%(13 / 30)$ had a poor score. The satisfactory rate was $50 \%(15 / 30)$. Evaluation based on the modified Mize criteria revealed $10 \%(3 / 30)$ of the patients had an excellent score, $40 \%(12 / 30)$ had a good score, $26.7 \%(8 / 30)$ had a fair score, and $23.3 \%$ (7/30) demonstrated failure. The satisfactory rate was $50 \%(15 / 30)$.

In the supracondylar group, the mean Knee Society knee score was 85.5 (range, 42-97); among them, $70.8 \%(17 / 24)$ had an excellent score, $16.7 \%(4 / 24)$ had a good score, $8.3 \%(2 / 24)$ had a fair score, and $4.2 \%(1 / 24)$ had a poor score. The satisfactory rate was $87.5 \%(21 / 24, P=0.009)$. The average Knee Society function score was 83.1 (range, 55-100); among these, $50 \%(12 / 24)$ had an excellent score, $25 \%(6 /$ 24) had a good score; $20.8 \%(5 / 24)$ had a fair score, and $4.2 \%(1 / 24)$ had a poor score. The satisfactory rate was $75 \%(18 / 24, P=0.023)$. Evaluation based on the modified Mize criteria revealed $29.1 \%(7 / 24)$ of the patients had an excellent score, $50 \%(12 / 24)$ had a good score, $16.7 \%(4 / 24)$ had a fair score, and $4.2 \%(1 / 24)$ demonstrated failure. The satisfactory rate was $79.1 \%(19 / 24, P=0.09)$.

The comparisons of clinical and functional outcomes are summarized in Tables 3 and 4 .

\section{Discussion}

Fractures of the distal femur account for $6 \%$ of all femur fractures and is clinically challenging. Sufficient mechanical stability is required in the treatment of distal femur fractures; thus, patients should receive early rehabilitation to achieve better clinical outcome. At present, fixation options include nailing systems and plating systems. Intramedullary nailing can be performed in retrograde pattern. Advantages of intramedullary nailing include less extensive dissection, decreased blood loss, and decreased operating time [19]. Some studies suggest that retrograde nailing leads to a higher union rate than that achieved with plating [20-22]. Plating techniques have the advantage of achieving anatomic reduction through a direct view of the fracture site. However, the possibility of invasive incision and soft tissue dissection

Table 3 Clinical outcomes

\begin{tabular}{llll}
\hline Parameter & Supraintercondylar & Supracondylar & $P$ value \\
\hline Union rate & $90 \%(27 / 30)$ & $91.7 \%(22 / 24)$ & 0.68 \\
$\begin{array}{l}\text { Time to union, mean } \\
\text { (range), months }\end{array}$ & $6.4(2-12)$ & $5(3-10)$ & 0.19 \\
$\begin{array}{l}\text { Complications } \\
\quad \text { Infection }\end{array}$ & $6.7 \%(2 / 30)$ & $0 \%$ & 0.30 \\
$\quad \begin{array}{l}\text { Stiffness (knee flexion } \\
\left.<90^{\circ}\right)\end{array}$ & $13.3 \%(4 / 30)$ & $0 \%$ & 0.09 \\
$\quad$ Varus deformity & $16.7 \%(5 / 30)$ & $0 \%$ & 0.045 \\
\hline
\end{tabular}


Table 4 Functional outcomes

\begin{tabular}{llll}
\hline Parameter & Supraintercondylar & Supracondylar & $P$ value \\
\hline Knee Society Score (Knee score) & & \\
Average score & 73.6 & 85.5 & 0.009 \\
Excellent & $50 \%(15 / 30)$ & $70.8 \%(17 / 24)$ & \\
Good & $23.3 \%(7 / 30)$ & $16.7 \%(4 / 24)$ & \\
Fair & $13.3 \%(4 / 30)$ & $8.3 \%(2 / 24)$ & \\
Poor & $13.3 \%(4 / 30)$ & $4.2 \%(1 / 24)$ & \\
(Function score) & & & 0.023 \\
Average score & 62.5 & 83.1 & \\
Excellent & $46.7 \%(14 / 30)$ & $50 \%(12 / 24)$ & \\
Good & $3.3 \%(1 / 30)$ & $25 \%(6 / 24)$ & \\
Fair & $6.7 \%(2 / 30)$ & $20.8 \%(5 / 24)$ & \\
Poor & $43.3 \%(13 / 30)$ & $4.2 \%(1 / 24)$ & \\
Modified Mize Score & & & \\
Excellent & $10 \%(3 / 30)$ & $29.1 \%(7 / 24)$ & \\
Good & $40 \%(12 / 30)$ & $50 \%(12 / 24)$ & \\
Fair & $26.7 \%(8 / 30)$ & $16.7 \%(4 / 24)$ & \\
Poor & $23.3 \%(7 / 30)$ & $4.2 \%(1 / 24)$ & \\
\hline
\end{tabular}

may lead to complications, including nonunion or delayed union. Locking plate with lateral MIPO approach can have less soft tissue dissection and may not need to expose fracture site. With this technique and modern implant, the possibility of delayed union or nonunion can be decreased. Due to patient's economic status, condylar buttress plate in the treatment of distal femur still plays a role in our country.

In our previous study, we concluded that the use of a CBP in the treatment of supraintercondylar femur fracture can achieve a union rate of $90 \%$ [12]. However, 5 of 30 patients were noted to have varus deformity after surgery, which equals to an incidence of $16.7 \%$. In other words, a CBP may not provide enough stability for fixation of supraintercondylar fracture. Davidson and colleagues also reported varus collapse of comminuted distal femur fracture after treatment with a CBP [23]. We further collected data on patients with supracondylar fracture who received treatment with a CBP. We found that these patients achieved a union rate of $91 \%$ and no postoperative malalignment, including varus or valgus deformity. In other words, supraintercondylar femur fractures treated with a CBP lead to $16.7 \%$ postoperative varus deformity, but none occurred in supracondylar femur fractures. The reason for this difference may be that loads on the medial compartment of the knee are much greater than those on the lateral aspect of the knee during the stance phase of gait $[16,17]$. The screws that are laterally applied in a CBP may not provide sufficient stability for the medial aspect of supraintercondylar fracture fragments, thus resulting in medial side collapse with varus malalignment. Therefore, double plating may be a possible treatment for supraintercondylar femur fracture. Sanders and colleagues reported good-to-fair functional outcome and a $100 \%$ healing rate in 9 patients with unstable comminuted distal femur fracture treated with double plating and bone grafting [24]. However, in order to fix fracture fragments with plates in both lateral and medial aspects of the femur, there may be too much soft tissue dissection periosteally. Theoretically, it introduces a high nonunion rate. Ziran and colleagues reported plating on anterior and lateral sides through an anterior approach in order to minimize stripping of the medial side of the femur [11]. Nevertheless, supracondylar fracture does not require fixation of medial fragments.

Rademakers and colleagues reported on 67 patients with distal femur fracture treated with a fixed-angle condylar plate [25]. Only 1 patient had nonunion at postoperative 1-year. As for functional outcome, goodto-excellent results were achieved in $84 \%$ based on the Neer score, $75 \%$ based on the Hospital for Special Surgery knee score, and $72 \%$ based on the Ahlbäck score. Dar and colleagues reported on 68 distal femur fractures, including AO/OTA types $\mathrm{A}$ and $\mathrm{C}$, treated with dynamic condylar screwing or retrograde intramedullary supracondylar nailing [24]. Union rates of $87.5 \%$ and $89 \%$ were achieved in the dynamic condylar screwing and retrograde nailing groups, respectively. There were no differences between the 2 groups in terms of cumulative union rate, range of motion, complications, or overall results. However, the dynamic condylar screwing group required less time to complete the operation, and there was less blood loss in the retrograde nailing group. Petastodis and colleagues reported on 116 distal femur fractures, including supracondylar and intra-articular involvement, treated with ORIF with 1 of the following 3 implants: CBP, fixed-angle condylar blade plate, or dynamic condylar screwing [10]. They concluded that dynamic condylar screw fixation achieved better functional outcome and lower complication rate compared with CBP and fixed-angle condylar blade plate fixation. Ninety-six percent of patients attained good-to-excellent results. Treatment with dynamic condylar screws is less technically demanding and easier to perform, but removes a large amount of the distal bone stock.

Theoretically, distal femur fractures treated with a locking plate may have more sufficient stability. Therefore, better clinical and functional outcomes may be expected, compared with the current plating system. However, such complications as nonunion, delayed union, and implant failure are not infrequent in distal femur fractures treated with locking plates. Nonunion rates of $0-19 \%$, delayed union rates of $0-15 \%$, and implant failure rates of $0-20 \%$ were reported by 
Henderson and colleagues [11]. There is no consensus over which implant is significantly superior over other implants. Every device has its own advantages and disadvantages. Thus, surgeons should understand the different characteristics of each implant and choose the one they are most familiar working with and that which is most appropriate for the patient.

There are several limitations in our study. The retrospective nature and paucity of patient number make significant relevance less optimal. Thirty-three out of 87 patients were excuded from our series due to loss of follow up and results may be affected if they have enough follow-up periods. Besides, surgeries were not performed by the same surgeon and, therefore, technical familiarity might have affected the results. In order to obtain better evidence of the treatment outcomes, larger patient number and longer follow-up time may be necessary.

\section{Conclusion}

CBPs can achieve a high union rate $(>90 \%)$ in the treatment of both supraintercondylar and supracondylar femur fractures. However, $16.7 \%$ of patients with supraintercondylar fracture developed postoperative varus deformity. On the contrary, no patient with supracondylar fracture developed this deformity. Moreover, CBP treatment in patients with supracondylar fractures resulted in better functional outcomes than in those with supraintercondylar fractures.

\section{Abbreviations \\ CBP: Condylar buttress plate; LDFA: Lateral distal femoral angle; ORIF: Open reduction and internal fixation}

\section{Acknowledgements}

None.

\section{Funding}

No funding was obtained.

\section{Availability of data and materials}

All the data is contained within the manuscript.

\section{Authors' contributions \\ CJW participated in data acquisition and writing of the manuscript. CCW participated in study conception and review of the manuscript. KFF participated in study design and review of manuscript. ICT participated in data acquisition and review of the manuscript. PCL participated in study design and conception. YCH participated in review and correction of the manuscript. All authors read and approved the final manuscript.}

\section{Competing interests}

All authors declare that they have no competing interests.

\section{Consent for publication}

Not applicable.

\section{Ethics approval and consent to participate}

This study had been approved by the Chang Gung Memorial Hospital review board (100-0052B). All patients had given written informed consent for the evaluation and publication of their data as part of the informed consent for the operation.
Received: 22 November 2015 Accepted: 30 September 2016

Published online: 04 October 2016

\section{References}

1. Stewart MJ, Sisk D, Wallae SL. Fractures of the distal third of the femur. A comparison of methods of treatment. J Bone Joint Surg Am. 1966:48:95-104.

2. Neer 2nd CS, Grantham SA, Shelton ML. Supracondylar fracture of the adult femur. A study of one hundred and ten cases. J Bone Joint Surg Am. 1967; 49(4):591-613

3. Schatzker J, Lambert DC. Supracondylar fractures of the femur. Clin Orthop Relat Res. 1979;138:77-83.

4. Giles JB, DeLee JC, Heckman JD, Keever JE. Supracondylar-intercondylar fractures of the femur treated with a supracondylar plate and lag screw. J Bone Joint Surg Am. 1982;64(6):864-70.

5. Mize RD, Bucholz RW, Grogan DP. Surgical treatment of displaced, comminuted fractures of the distal end of the femur. J Bone Joint Surg Am. 1982;64(6):871-9.

6. Mize RD. Surgical management of complex fractures of the distal femur. Clin Orthop Relat Res. 1989:240:77-86.

7. Sanders R, Regazzoni P, Ruedi TP. Treatment of supracondylar-intracondylar fractures of the femur using the dynamic condylar screw. J Orthop Trauma. 1989;3(3):214-22.

8. Sanders R, Swiontkowski M, Rosen H, Helfet D. Double-plating of comminuted, unstable fractures of the distal part of the femur. J Bone Joint Surg Am. 1991:73(3):341-6.

9. Kolb K, Grutzner P, Koller H, Windisch C, Marx F, Kolb W. The condylar plate for treatment of distal femoral fractures: a long-term follow-up study. Injury. 2009;40(4):440-8. doi:10.1016/j.injury.2008.08.046.

10. Petsatodis $G$, Chatzisymeon A, Antonarakos P, Givissis P, Papadopoulos P, Christodoulou A. Condylar buttress plate versus fixed angle condylar blade plate versus dynamic condylar screw for supracondylar intra-articular distal femoral fractures. J Orthop Surg (Hong Kong). 2010;18(1):35-8.

11. Henderson CE, Kuhl LL, Fitzpatrick DC, Marsh JL. Locking plates for distal femur fractures: is there a problem with fracture healing? J Orthop Trauma. 2011;25 Suppl 1:S8-14. doi:10.1097/BOT.0b013e3182070127.

12. Weng CJ, Wu CC, Feng KF, Tseng IC, Lee PC, Huang YC. High incidence of varus deformity in association with condylar buttress plates used to treat supraintercondylar fracture of the femur. Formosan J Musculoskelet Disord. 2012;3:50-5.

13. Marsh JL, Slongo TF, Agel J, Broderick JS, Creevey W, DeCoster TA, et al. Fracture and dislocation classification compendium - 2007: Orthopaedic Trauma Association classification, database and outcomes committee. J Orthop Trauma. 2007;21(10 Suppl):S1-133.

14. Keats TE, Teeslink R, Diamond AE, Williams JH. Normal axial relationships of the major joints. Radiology. 1966;87(5):904-7.

15. Bucholz RW, Heckman JD, Court-Brown CM, Tornetta III P. Rockwood and Green's Fractures in Adults. 7 ed. 2009.

16. Andriacchi TP. Dynamics of knee malalignment. Orthop Clin North Am. 1994:25(3):395-403.

17. Zhao D, Banks SA, Mitchell KH, D'Lima DD, Colwell Jr CW, Fregly BJ. Correlation between the knee adduction torque and medial contact force for a variety of gait patterns. J Orthop Res. 2007;25(6):789-97. doi:10.1002/jor.20379.

18. Insall JN, Dorr LD, Scott RD, Scott WN. Rationale of the Knee Society clinical rating system. Clin Orthop Relat Res. 1989:248:13-4.

19. Kim J, Kang SB, Nam K, Rhee SH, Won JW, Han HS. Retrograde intramedullary nailing for distal femur fracture with osteoporosis. Clin Orthop Surg. 2012;4(4):307-12. doi:10.4055/cios.2012.4.4.307.

20. Heiney JP, Barnett MD, Vrabec GA, Schoenfeld AJ, Baji A, Njus GO. Distal femoral fixation: a biomechanical comparison of trigen retrograde intramedullary (i.m.) nail, dynamic condylar screw (DCS), and locking compression plate (LCP) condylar plate. J Trauma. 2009;66(2):443-9. doi:10.1097/TA.0b013e31815edeb8.

21. Zlowodzki M, Bhandari M, Marek DJ, Cole PA, Kregor PJ. Operative treatment of acute distal femur fractures: systematic review of 2 comparative studies and 45 case series (1989 to 2005). J Orthop Trauma. 2006;20(5):366-71.

22. Herrera DA, Kregor PJ, Cole PA, Levy BA, Jonsson A, Zlowodzki M. Treatment of acute distal femur fractures above a total knee arthroplasty: systematic review of 415 cases (1981-2006). Acta Orthop. 2008:79(1):22-7. doi:10.1080/17453670710014716. 
23. Davison BL. Varus collapse of comminuted distal femur fractures after open reduction and internal fixation with a lateral condylar buttress plate. Am J Orthop (Belle Mead NJ). 2003;32(1):27-30.

24. Dar GN, Tak SR, Kangoo KA, Halwai MA. Bridge plate osteosynthesis using dynamic condylar screw (DCS) or retrograde intramedullary supracondylar nail (RIMSN) in the treatment of distal femoral fractures: comparison of two methods in a prospective randomized study. Ulus Travma Acil Cerrahi Derg. 2009;15(2):148-53.

25. Rademakers MV, Kerkhoffs GM, Sierevelt IN, Raaymakers EL, Marti RK. Intraarticular fractures of the distal femur: a long-term follow-up study of surgically treated patients. J Orthop Trauma. 2004;18(4):213-9.

Submit your next manuscript to BioMed Central and we will help you at every step:

- We accept pre-submission inquiries

- Our selector tool helps you to find the most relevant journal

- We provide round the clock customer support

- Convenient online submission

- Thorough peer review

- Inclusion in PubMed and all major indexing services

- Maximum visibility for your research

Submit your manuscript at www.biomedcentral.com/submit
Biomed Central 